\title{
O conceito de Estado em René Zavaleta e a influência de Antonio Gramsci
}

\author{
The concept of State in René Zavaleta and the influence of Antonio \\ Gramsci
}

\section{Lauro Allan Almeida Duvoisin Sonia Maria Ranincheski}

\section{Resumo}

O objetivo deste artigo é analisar a contribuição de René Zavaleta Mercado para a compreensão da problemática do Estado na América Latina, buscando identificar a influência de Gramsci em suas obras. Analisamos três artigos do autor: Problemas de la determinación dependiente y la forma primordial; El Estado en América Latina e; Formas de operar del Estado en América Latina (bonapartismo, populismo, autoritarismo). Verificamos a forte influência de Gramsci sobre a obra de Zavaleta. Em especial, percebe-se que ambos se inserem no debate marxista sobre o papel da superestrutura na manutenção ou transformação da sociedade. Contudo, verifica-se também um forte grau de originalidade na operacionalização de alguns conceitos que o sociólogo boliviano propóe ao analisar a realidade latino-americana. Destaca-se, ademais, a grande preocupação de Zavaleta em compreender as diferentes formas assumidas pelos Estados em conformidade com suas especificidades nacionais.

\section{Palavras-chave}

América Latina; Estado; Antonio Gramsci; René Zavaleta.

\section{Abstract}

The objective of this article is to analyze the René Zavaleta Mercado's contribution to the understanding of the State problematic in Latin America, seeking to identify the influence of Gramsci in his works. We have analyzed three articles by the author: Problems of dependent determination and primordial form; The State in Latin America; Forms of state operations in Latin America (bonapartism, populism, authoritarianism). We see the strong influence of Gramsci on the work of Zavaleta. In particular, it can be seen that both are inserted in the marxist controversy over the role of the superstructure in the maintenance or transformation of society. However, there is also a strong degree of originality in bolivian sociologist proposal when analyzing the Latin American reality. It is also worth mentioning Zavaleta's great concern to understand the different forms assumed by States in accordance with their national characteristics.

\section{Keywords}

Latin America; State; Antonio Gramsci; René Zavaleta. 


\section{Introdução $^{1}$}

As interpretaçôes latino-americanas do pensamento de Gramsci foram se formando tomando como base, principalmente, a realidade de desigualdade e exploração social reinante no continente. As ideias do comunista italiano circularam entre os latino-americanos e foram incorporadas de maneira singular de acordo com os diferentes contextos históricos nacionais, mas com repercussões notáveis (ARICÓ, 1998; PORTANTIERO, 1981). É difícil distinguir a sua disseminação no meio acadêmico da sua influência nas organizações políticas de esquerda latino-americanas. Afinal, foi a partir dos debates internos do movimento comunista que Gramsci se fez conhecido mundialmente. Lincoln Secco aponta que no Brasil as suas ideias passaram a ser difundidas nos anos 1950 pela imprensa comunista que buscava construir a imagem de um Gramsci partidário (SECCO, 2000). Ou seja, o conteúdo veiculado permanecia limitado pela doutrina oficial da III Internacional. No âmbito acadêmico, a sua influência inicial se deu em torno do conceito de hegemonia (ARICÓ, 1998). Além disso, o acesso a Gramsci também se deu por intermédio da obra de Althusser e sua grande disseminação no meio universitário.

A Argentina foi o primeiro país, fora da Itália, a traduzir e estudar a obra do dirigente italiano (CAMPIONE, 2007), demonstrando a precoce recepção de seu pensamento na América Latina. Hector Agosti foi o responsável pela publicação das Cartas do Cárcere, em 1950, e, entre 1958 e 1962, dos Cadernos do Cárcere. Nessa mesma época, o nome de Gramsci tornou-se mundialmente conhecido. Certamente, Gramsci pode ser tomado como um exemplo de apropriação e aplicação do método de Marx para interpretar a sua própria realidade. O seu potencial para compreender a realidade latino-americana adviria da capacidade de traduçáo dos seus conceitos para realidades distintas da italiana, o que podemos definir como uma certa plasticidade do pensamento gramsciano. Assim, diversos conceitos com abordagem gramsciana têm sido empregados de maneira promissora no estudo da realidade latino-americana, como hegemonia, crise de hegemonia, sociedade civil e sociedade política, transformismo político e revolução passiva. Recentemente, por exemplo, autores têm retomado conceitos gramscianos como hegemonia e Estado para compreender o avanço das forças conservadoras em países do nosso continente neste primeiro decênio do século XXI (MUNCK, 2015; PIZZORNO, 2017).

\footnotetext{
${ }^{1}$ Agradecemos ao colega Leonardo Granato pelas valiosas sugestôes.
} 
Destas visões gramscianas, o pensamento do sociólogo boliviano René Zavaleta se destaca pela influência tanto no meio acadêmico, ao exercer a direção da Flacso nos anos 80, quanto fora dele. Pouco conhecido entre os brasileiros, Zavaleta é considerado um dos grandes pensadores latino-americanos. Inspirou geraçóes de intelectuais, acadêmicos e políticos tanto no seu país de origem, a Bolívia, como em outras nações. Dentre eles, podemos citar o atual vice-presidente boliviano, Álvaro Garcia Linera (RADA, 2014; WILLIAMS, 2015).

Um dos temas abordados por Zavaleta foi a questão do Estado, tendo em Gramsci a inspiração para pensar o continente latino-americano ${ }^{2}$. Como foi a recepção por Zavaleta da obra de Gramsci? Como se apropriou dos conceitos de Gramsci e os considerou para a realidade latino-americana? Este artigo tem por objetivo analisar em que medida e quais aspectos do pensamento de Antonio Gramsci foram apropriados por René Zavaleta na discussão que este autor desenvolve em torno do conceito de Estado. Trata-se do trabalho de rastrear a influência de um importante pensador europeu sobre as reflexóes de um intelectual latino-americano que pensou as particularidades dos Estados no nosso continente.

Faremos a análise de três artigos de Zavaleta que se dedicam a discutir com centralidade o tema do Estado: Problemas de la determinación dependiente y la forma primordial, publicado pela primeira vez em 1982 (ZAVALETA, 2009); El Estado en América Latina, publicado originalmente em 1983 (ZAVALETA, 1990); Formas de operar del Estado en América Latina (bonapartismo, populismo, autoritarismo), publicado pela primeira vez em 2006 (ZAVALETA, 2006).

\section{Quem foi René Zavaleta}

Infelizmente não contamos com nenhum trabalho biográfico completo sobre a trajetória de René Zavaleta. As informaçóes sobre sua vida pessoal e profissional ainda encontram-se esparsas em diversos artigos publicados por seus antigos colegas de trabalho e estudiosos de sua obra ${ }^{3}$. Boliviano de origem, dedicou-se a atividades políticas e intelectuais no âmbito da esquerda de seu país. Zavaleta nasceu em Oruro em 1937, "la ciudad más proletarizada de Bolivia" (PACHECO, 2006, p. 66). Aos 16 anos de idade, deixou a casa de seus pais para ir morar em La Paz e acompanhar de perto a revolução que iniciava com a chegada de Victor Paz Estenssoro ao poder.

\footnotetext{
${ }^{2}$ Outros pesquisadores já apontaram a influência de Gramsci nos escritos de Zavaleta sobre o Estado. Ver Cabaluz (2018) e Rojas (2017).

${ }^{3}$ Alguns desses artigos encontram-se na coletânea publicada por Ibargüen e Méndez (2006).
} 
Participou ativamente deste processo que instaurou um governo modernizador, distributivo e com intensa participação popular, liderado pelo Movimento Nacionalista Revolucionário (MNR). Encontrou trabalho no jornal La Nación que aglutinava importantes quadros intelectuais ligados ao movimento nacionalista boliviano. Aos 21 anos de idade tornou-se subdiretor do mesmo jornal e aos 24 elegeu-se deputado. Três anos depois veio a ocupar o cargo de Ministro de Minas e Petróleo do governo revolucionário.

Grande parte da obra do sociólogo está marcada por esta experiência que foi derrotada por um golpe militar em 1964, em tal profundidade que

escribió con carácter de pertenencia vital, de modo acentuadamente autobiográfico, el proceso revolucionario boliviano de 1952, el papel político del Movimiento Nacionalista Revolucionario (MNR) en el que militó y el esfuerzo de pertenecerse intelectualmente a sí mismo, alcanzando la forma de una profunda revisión del marxismo y en general del desarrollo de la teoría política en Bolivia (MORALES, 2006, p. 113).

O impacto da derrota da Revolução de 1952 sobre a produção intelectual de Zavaleta tem um interessante paralelo com os efeitos que a derrota comunista e a ascensão do fascismo na Itália tiveram sobre o pensamento de Gramsci (TAPIA, 2009a). Em ambos os casos, a derrota resultou em uma rica produção e amadurecimento intelectual. Já no exílio, estando encerrada a experiência nacionalista boliviana, e tendo-se consolidado como pensador de seu país, Zavaleta iria desenvolver sua carreira na Inglaterra e no México. Ele atuou na Universidade de Oxford de 1969 a 1971 (BÓRQUEZ, 2006), Universidade Nacional Autônoma do México e na Universidade Autônoma Metropolitana. Destacou-se também por ter sido o primeiro diretor da Faculdade Latino-Americana de Ciências Sociais (FLACSO), de 1976 até 1984. Zavaleta faleceu em 1984, com 47 anos de idade, num momento que alguns consideram de plena maturidade intelectual.

A produção intelectual de Zavaleta é ampla, abrangendo 13 livros, 29 capítulos de livros e artigos em revistas, 93 artigos jornalísticos e alguns manuscritos ainda não publicados (TAPIA, 2009b). Tanto a biografia quanto a produção acadêmica do autor permitem-nos afirmar que ele foi um pensador engajado no esforço de compreensáo da realidade latino-americana, seu locus privilegiado de análise. Segundo Tapia, "su producción se centra en pensar los problemas históricos estructurales de la nación como construcción histórica, y los problemas del poder; si 
articulamos ambas cosas, los problemas de la construcción del poder como Estado, en particular como Estado-nación” (TAPIA, 2009a, p. 9-10). Seu leque de preocupaçóes foi vasto, abrangendo a discussão sobre a formação das nações e os nacionalismos, a inserção da América Latina no sistema econômico capitalista internacional, a questão da participação das massas na vida política nacional, o fascismo, o populismo e a formação dos Estados. Puchet dirá que "La nación fue su obsesión major" (PUCHET, 2006, p. 87). Percebe-se, portanto, que seus interesses de pesquisa sempre tiveram ênfase nos fenômenos políticos.

\section{O lugar do Estado na teoria social}

Zavaleta assim como Gramsci compartilhou uma preocupação teórica no interior da tradição marxista que diz respeito à relação entre a estrutura econômica e a superestrutura da sociedade. Esta "metáfora do edifício", nas palavras de Althusser (ALTHUSSER, 1974, p. 12), encontra-se em alguns textos de Marx, como no seu conhecido prefácio da Contribuição à crítica da economia política (MARX, 2008), e foi utilizada para explicar o sentido da determinação em última instância da base sobre a superestrutura. Vale notar que o sentido da metáfora de Marx não torna o seu pensamento necessariamente determinista, como pode ser deduzido da sua preocupação com a ação política, que aparece com prioridade em textos como $\mathrm{O} 18$ Brumário de Luís Bonaparte (MARX, 2011).

Gramsci sem dúvida é herdeiro dessa discussão. As suas duas principais proposiçôes a respeito do assunto podem ser expressas da seguinte maneira: 1) o nível da sociedade que se define como superestrutura (o Estado, o aspecto políticoideológico, jurídico...) tem sua própria história e dinâmica específica; 2) a estrutura está organicamente vinculada à superestrutura e a sua reprodução depende de certas condiçôes produzidas na superestrutura. Neste sentido, fazendo sua própria leitura da obra de Marx, afirmou Gramsci:

¿Cómo habría podido pensar Marx que las superestructuras son apariencia e ilusión? Incluso sus doctrinas son una superestructura. Marx afirma explícitamente que los hombres toman conciencia de sus obligaciones en el terreno ideológico de las superestructuras, lo cual no es pequeña afirmación de "realidad": su teoría quiere también ella precisamente "hacer tomar conciencia" de las propias obligaciones. De la propia fuerza, del propio devenir, a un determinado grupo social (GRAMSCI, 1999b, p. 149). 
Ou seja, Gramsci está preocupado, sobretudo, em afirmar a autonomia relativa do político em relação à estrutura econômica da sociedade. Neste sentido, ele é categórico: "La pretensión (presentada como postulado esencial del materialismo histórico) de presentar y exponer toda fluctuación de la política y la ideología como una expresión inmediata de la estructura, debe ser combatida teóricamente como un infantilismo primitivo" (GRAMSCI, 1968, p. 161). O apelo à Marx indica justamente com quem ele está dialogando. Tratava-se de responder àqueles intérpretes que conduziram o marxismo a uma vulgarização, reduzindo a complexidade do pensamento original de Marx a uma mera determinação econômica sobre as outras esferas da sociedade ${ }^{4}$. Por outro lado, a interpretação de Gramsci não conduzia a uma negação da ideia de determinação. Desse modo, Gramsci não nega a visão geral de sociedade elaborada pelo marxismo.

Significativo é o fato de Zavaleta problematizar a realidade social em termos similares aos de Gramsci, pois continua lidando com os conceitos de estrutura e superestrutura, tal qual o pensador italiano. Ademais, é também significativo que o sociólogo boliviano proponha uma solução similar para compreender a relação entre esses dois níveis de análise. Ambos os aspectos revelam a influência que Gramsci exerceu sobre Zavaleta. Assim, tal qual Gramsci, Zavaleta não nega a existência de determinações da estrutura econômica, típica da tradição marxista de análise, mas percebe a existência de uma dinâmica própria e particular da superestrutura. Em seu artigo Formas de operar del Estado en América Latina (bonapartismo, populismo, autoritarismo) fica evidente a sua abordagem:

No siempre la superestructura corresponde en todos los momentos a la base; todo lo contrario. Pero ello es tan cierto como que, cuando existe el acto económico o la relación productiva, existen a la vez dentro de ellos, y no como un rebote, las relaciones estatales y los episodios de la representación social. De esta manera, la circulación ideológica, el mercado, creará el inconsciente estatal, que es la ideología, y no hay duda tampoco de que el Estado es la atmósfera de la producción, o sea, caso flagrante, tenemos aquí una valencia infraestructural de un hecho tan constitucionalmente superestructural como el Estado (ZAVALETA, 2006, p. 35).

\footnotetext{
${ }^{4}$ Para uma discussão sobre o marxismo vulgar ver Hobsbawm (1998).
} 
Ou seja, Zavaleta parece perceber a existência de uma correspondência entre os momentos da estrutura e os da superestrutura, mas esta correspondência não é automática nem imediata. Do mesmo modo, em seu artigo Problemas de la determinación dependiente y la forma primordial, ao buscar caracterizar o imperialismo imposto aos países da América Latina pelas potências centrais, Zavaleta comenta que "una determinación estructural está siempre revelada por su forma ideológica y la combinatoria de ambas, estructura e ideología, debe producir siempre una política" (ZAVALETA, 2009, p. 113). Esta observação do autor não é nada trivial. Ela nos diz muito sobre as consequências políticas de uma formação social dependente e voltada para a acumulação externa. Ou seja, a forma política tem seu paralelo na forma econômica, sendo que a aparente exterioridade do Estado frente à sociedade em contextos marcados pela dependência é resultado da própria exterioridade de seu sentido econômico de existência.

Contudo, ainda assim o político não é redutível à estrutura econômica. Zavaleta busca mais uma vez em Gramsci a explicação para esta não redução. Trata-se da natureza histórica sobre a qual as sociedades se constroem. Como se sabe, para Gramsci o terreno de realização da filosofia era a história, entendida como um devir aberto à ação humana. Diz ele, "El materialismo histórico, tal como es, es el aspecto popular del historicismo moderno" (GRAMSCI, 1999b, p. 136). Quem dizer, a história é tanto o terreno de realização das visóes de mundo em luta no plano ideológico da sociedade quanto é, ao mesmo tempo, o lugar de verificação das teorias sobre a sociedade. Neste sentido, sem dúvida as verdades científicas para Gramsci tinham um estatuto histórico sendo, portanto, mutáveis. É por isso que o pensador italiano iria afirmar "La ciencia es también ella una superestructura" (GRAMSCI, 1999b, p. 142).

Seguindo as pistas deixadas por Gramsci, Zavaleta conceberá o Estado, como espaço político da superestrutura, através de sua historicidade. Ele não vê o Estado como uma organização acabada, senão muito mais como um longo processo histórico de lutas e acomodaçóes possíveis inseridas no contexto geral do continente latinoamericano, mas com marcas nacionais que resultaram em conformações específicas. Daí porque uma das preocupaçóes centrais do autor é compreender as particularidades de cada um dos Estados, dando atenção àquilo que os diferencia das experiências vizinhas.

A mensagem de Zavaleta é clara: "Después de Gramsci no se puede imaginar dominación alguna que sea estable, ni aun del modo más relativo, al margen de tal razonamiento. En la política, el sueño de las victorias totales es tan absurdo como en 
la guerra" (ZAVALETA, 1990, p. 171). Estamos aqui no terreno da história como processo aberto realizado pelas açóes humanas. Conforme observa Tapia,

En este sentido, hay cierto parecido con el trabajo de Antonio Gramsci, es decir, la renovación en el pensamiento viene del intento de explicar primero por qué fracasaron la estrategia política previa y el modo de pensar el Estado, el poder y la construcción de un nuevo tipo de sociedad (TAPIA, 2009a, p. 13).

Haveria um estado de latência de uma ruptura da ordem e a sua potencial transformação.

Para o sociólogo boliviano, a superestrutura comporta a originalidade das experiências nacionais a despeito de sua subsunção ao capitalismo global. Neste ponto, um dos conceitos chave mobilizados pelo autor é o de formação econômicosocial:

La superestructura, se dice, debe ser autóctona, o sea que es originaria en su naturaleza. Se puede prolongar este razonamiento y decir que la superestructura expresa la diversidad de la historia del mundo. No puede hablarse de ella como regularidad o mismidad en cuanto al modelo de reiteración o paradigma del modo de producción capitalista, pues su carácter está dado por el sesgo articulatorio o formación económico-social (ZAVALETA, 2009, p. 302).

O conceito de formação econômico-social foi desenvolvido por alguns teóricos marxistas a partir da constatação de que o conceito de modo de produção era excessivamente abstrato para dar conta de algumas particularidades nacionais, especialmente para as regióes de capitalismo tardio e periférico (CUEVA, OBERDIEK e TOMAZI, 1997; QUEVEDO, 2014). Está evidente na visão de Zavaleta que a formação econômico-social determina as funções do Estado e a forma como ele se estrutura, sugerindo não ser possível fazer uma transposição direta dos modelos explicativos desenvolvidos nos países centrais para as regiôes periféricas. Não se encontra em Gramsci o uso do conceito de formação econômico-social, mas o conteúdo deste conceito busca responder a problemas similares aos que Gramsci havia tratado em sua obra. 
114 | Lauro Allan Almeida Duvoisin e Sonia Maria Ranincheski

\section{Teoria de Estado em Gramsci e em Zavaleta}

Para enfrentar o objetivo principal deste artigo, que é o de identificar a influência do pensamento gramsciano sobre a discussão que Zavaleta empreende em torno do conceito de Estado, há que se reconhecer a visão de Estado de ambos. Em primeiro lugar, talvez seja útil perguntar se se encontra em Gramsci uma teoria geral do Estado. Como se sabe, ainda que Marx tenha deixado importantes escritos políticos, não chegou a desenvolver algo como uma teoria do Estado. Assim, somente com Lenin a questão do Estado começou a ser desenvolvida dentro da perspectiva marxista. Gramsci apoia-se em grande parte na contribuição de Lenin para desenvolver suas ideias sobre este tema.

Para Gramsci, não só os contextos históricos nos quais o Estado é construído são diferentes, mas as próprias forças sociais implicadas no processo podem ser distintas. Essas diferenças, porém, não invalidam a vinculação do Estado com as classes sociais produtivas. Para Gramsci, não haveria uma absolutização do Estado, mas ele - o Estado - seria formado por "dos grandes 'planos' superestructurales, el que se puede llamar de la 'sociedad civil', o sea del conjunto de organismos vulgarmente llamados 'privados', y el de la 'sociedad política o Estado"' (GRAMSCI, 1986, p. 357). Ao criticar a concepção liberal do Estado, o pensador italiano observa que

Estamos siempre en el terreno de la identificación de Estado y Gobiemo, identificación que, precisamente, es una representación de la forma corporativa-económica, o sea de la confusión entre sociedad civil y sociedad política, porque hay que observar que en la noción general de Estado entran elementos que deben reconducirse a la noción de sociedad civil (en el sentido, podría decirse, de que Estado = sociedad política + sociedad civil, o sea hegemonía acorazada de coerción). (GRAMSCI, 1968, p. 76).

Ou seja, encontra-se uma segunda acepção de Estado em Gramsci enquanto unidade de sociedade civil e sociedade política, um sentido ampliado que não se restringe ao conjunto de instituiçôes públicas.

Para Gramsci o Estado, que abarca sociedade civil e sociedade política, é o lugar de atuação dos intelectuais. Assim ele amplia também sobremaneira o alcance da categoria de intelectual, incluindo todos aqueles agentes que cumprem funções organizativas, conectivas e ideológicas na sociedade. Por isso, em Gramsci o Estado não aparece vinculado diretamente às classes, uma vez que ele está dependente da mediação que os intelectuais estabelecem entre Estado e classes sociais. 


\title{
De acordo com Buci-Gluksmann
}

\begin{abstract}
É verdade que, no curso de seu trabalho, Gramsci distinguirá progressivamente dois conceitos de Estado, ou mais precisamente dois momentos da articulação do campo estatal: o Estado em sentido estreito (unilateral), e o Estado em sentido amplo, dito integral. Em um sentido estreito, o Estado se identifica com o governo, com o aparelho de ditadura de classe, na medida em que ele possui funçóes coercitivas e econômicas. A dominação de classe se exerce através do aparelho de Estado no sentido clássico (exército, polícia, administração, burocracia). Mas essa função coercitiva é inseparável de um certo papel adaptativoeducativo do Estado, que procura realizar uma adequação entre aparelho produtivo e moralidade das massas populares (BUCI-GLUCKSMANN, 1980, p. 127-128).
\end{abstract}

Podemos, portanto, afirmar que a concepção de Estado em Gramsci desenvolve-se como o conjunto da superestrutura da sociedade, determinada pela estrutura econômica, mas que tem sua própria dinâmica interna. Ele se distancia da visão liberal, que concebe o Estado como espaço neutro e apartado da sociedade. No entanto, ressalta-se que Gramsci nega também a concepção instrumental de Estado, que concebe-o como mero objeto dos interesses de classe. Ou seja, na visão do filósofo italiano não é possível entender o Estado apartado de sua dimensão ética e cultural, que não são levadas em conta pelas abordagens instrumentais. Daí que a noção de hegemonia seja central para Gramsci, pois ela expressa a interpenetração entre o cultural e o político.

Para Gramsci, a distinção entre sociedade política e sociedade civil “(...) es puramente metodológica, no orgánica, y en la vida histórica concreta sociedad política y sociedad civil son una misma cosa" (GRAMSCI, 1999b, p. 172). Quer dizer, ele afirma o elemento de continuidade e unidade entre sociedade civil e sociedade política enquanto dois momentos ou níveis de organização do Estado. Por outro lado, em outros momentos ele observa que as relaçóes entre sociedade civil e sociedade política foram conflituosas no período histórico em que a afirmação da burguesia como classe dominante ainda era incipiente:

La división de poderes y toda la discusión producida por su realización y la dogmática jurídica nacida de su advenimiento, son el resultado de la lucha entre la sociedad civil y la sociedad política de un determinado periodo histórico, con un cierto equilibrio inestable de las clases, 
determinado por el hecho de que ciertas categorías de intelectuales (al servicio directo del Estado, especialmente burocracia civil y militar) están aún demasiado ligadas a las viejas clases dominantes (GRAMSCI, 1968, p. 66).

O pensador italiano referia-se aqui à experiência dos Estados ocidentais modernos onde a sociedade civil encontrava-se mais estruturada. Ou seja, para ele esse tipo de relação era específica e não necessariamente generalizável para outros tempos históricos e regióes geográficas. Isto fica claro na diferenciação feita entre países de tipo oriental e de tipo ocidental. Segundo ele,

En Oriente el Estado lo era todo, la sociedad civil era primitiva y gelatinosa; en Occidente, entre Estado y sociedad civil había una justa relación y en el temblor del Estado se dicernía de inmediato una robusta estructura de la sociedad civil. El Estado era sólo una trinchera avanzada, tras la cual se hallaba una robusta cadena de fortalezas y de casamatas (GRAMSCI, 1968, p. 157).

Por sua vez, destaca-se que Zavaleta enfrenta bastante explicitamente a polêmica sobre a validade de uma teoria geral de Estado para o estudo da América Latina. No seu artigo El Estado en America Latina (ZAVALETA, 1990) o autor dialoga com as teorias estruturalistas e instrumentalistas do marxismo, posicionandose contra a simples transposição de um modelo teórico generalizável para a América Latina. No entanto, o seu rechaço em reproduzir uma teoria geral não significa a negação de toda e qualquer teorização, nem mesmo a negação de que há regularidades entre as experiências históricas. Esta preocupação aparece no artigo Formas de operar del Estado en América Latina (bonapartismo, populismo, autoritarismo), em que o autor afirma:

El paradigma de Marx sobre el bonapartismo se funda en la historia francesa pero contiene algunos datos generalmente válidos para todo Estado moderno. Por consiguiente, nos servirá en la presente exposición para proponer: a) ciertas líneas principales en el análisis del Estado moderno, y b) algunas proposiciones en torno a la construcción de los paradigmas de la teoría política dentro del análisis marxista del Estado (ZAVALETA, 2006, p. 33-34, grifo nosso). 
Está claro, portanto, que ele procura encontrar uma posição intermediária entre a possibilidade de elaboração de uma teoria geral do Estado e a atenção às especificidades de cada Estado em particular. Da perspectiva de Zavaleta, as teorizações gerais sobre o Estado representam fundamentalmente generalizações de casos empíricos particulares, tendo portanto validade limitada.

O conceito de Estado para Zavaleta aparece em dois sentidos: um restrito e outro mais amplo. Assim como Gramsci, ele concebe o poder em duas esferas distintas, mas geralmente reserva o termo Estado ao sentido estrito ou emprega o termo "Estado político" (ZAVALETA, 2009, p. 312; ZAVALETA, 1990, p. 182) - o que para Gramsci seria a sociedade política - e não ao conjunto de aparatos públicos e privados. Nos três textos analisados, o termo "sociedade política” que Gramsci utiliza com frequência não aparece.

Por outro lado, percebe-se a ausência de um debate explícito de Zavaleta com os autores da tradição gramsciana. Curiosamente, ao tratar do problema estatal o sociólogo boliviano dialoga com Hegel, Gramsci, Hilferding, Lenin, Poulantzas, Habermas, Miliband e Offe, sem fazer menção a Christinne Buci-Glucksmann (BUCI-GLUCKSMANN, 1980), Hughes Portelli (PORTELLI, 2002), ou Juan Carlos Portantiero (PORTANTIERO, 1981), ou seja, a autores que utilizaram amplamente Gramsci e que a altura do início dos anos 1980 já tinham trabalhos publicados sobre o tema. Tendo em vista que é provável que o autor conhecesse esta produção e que enfrentou problemas teóricos similares a outros pensadores que se apropriaram das proposiçôes de Gramsci pode-se supor que ele trava uma espécie de debate implícito com eles.

Além disso, diferentemente de Gramsci, Zavaleta não chega a tratar da questão dos intelectuais nos três textos analisados, e essa ausência é significativa, pois a questáo dos intelectuais tem absoluta centralidade na discussão do Estado feita por Gramsci.

\section{O conceito de "equação social" ou "eixo estatal"}

Zavaleta parte da afirmaçáo de Gramsci de que haveria uma diferença fundamental entre as formaçôes estatais no oriente e no ocidente. Zavaleta vê nesta diferença uma chave para pensar as especificidades latino-americanas. Aliás, cabe destacar aqui que o debate sobre o caráter ocidental ou oriental dos Estados latinoamericanos tem um certo desenvolvimento, notavelmente ignorado por Zavaleta. 
Portantiero tratou da questão em sua obra publicada em 1981 (PORTANTIERO, 1981). Não há qualquer menção a ela nos textos de Zavaleta que analisamos. $\mathrm{Na}$ visão de Portantiero a noção gramsciana de ocidental versus oriental teria dois sentidos diferentes. A ideia de ocidente se refere primeiramente à "situación en la que la articulación entre economía, estructura de clases y estado asume forma equilibrada" (PORTANTIERO, 1981, p. 124). Todavia encontra-se um segundo sentido que teria como referência:

Sociedades, en fin, en las que la política tiene una influencia enorme en la configuración de los conflictos, modelando de algún modo a la sociedad, en un movimiento que puede esquematizarse como inverso al del caso anterior. Aquí, la relación economía, estructura de clases, política, no es lineal sino discontinua (PORTANTIERO, 1981, p. 125).

Em outras palavras, Portantiero observa que a noção de ocidente em Gramsci é mais complexa que pode parecer à primeira vista. Discussão similar foi desenvolvida por Carlos Nelson Coutinho, que endossa boa parte dos argumentos de Portantiero. Segundo ele, a distinção entre oriente e ocidente bem como o conceito de revolução passiva foram alguns dos eixos que favoreceram a apropriação de Gramsci no nosso continente e enriqueceram as interpretaçóes locais (COUTINHO, 2012). Existiriam duas grandes regióes da periferia capitalista, uma com características orientais e outra com características ocidentais, ainda que a última estivesse defasada em relação ao centro. Coutinho recorda que embora Gramsci em algumas de suas notas tenha tratado a América Latina como uma região de características orientais também já tinha notado algumas especificidades em função de seu desenvolvimento capitalista tardio. Tais especificidades permitiriam caracterizar as formaçôes estatais latinoamericanas como ocidentais periféricas:

Uma abordagem empírica, ainda que sumária, dos principais países de nosso continente revela que, nos últimos setenta anos, eles conheceram um processo de desenvolvimento que, malgrado suas inúmeras contradiçóes, transformou-os em países industrializados, nos quais o modo de produção dominante, inclusive na agricultura, é já há muito tempo o capitalismo. Além de uma numerosa e moderna classe operária, temos em nossas estruturas sociais a presença de amplas e diversificadas camadas médias assalariadas (COUTINHO, 2012, p. 8). 
Zavaleta segue um caminho original e parece não se aproximar de nenhuma dessas interpretaçóes. Se por um lado, ele mostrava-se cético quanto à possibilidade de tomar como referência analítica para a América Latina as experiências dos países avançados da Europa ocidental, também lhe parece insuficiente uma simples transposição do modelo oriental onde se encontraria, segundo Gramsci, um Estado forte e uma sociedade civil gelatinosa. Por isso, o boliviano pondera:

Además, hay formas de lo gelatinoso. Gelatinosa, por ejemplo, es una sociedad incapaz de producir opinión pública, y lo es sin duda aquella en que no se dan las condiciones para producir formas racionalcomprobables del poder. El capitalismo organizado produce sin excepción formas modernas de sociedad gelatinosa. En el caso de ciertos países como Perú y Bolivia, el verdadero problema no está en la gelatinosidad de lo social, sino en su osificación: la sociedad sigue sometida a la profundidad de su momento constitutivo, porque sin duda lo más importante que ha ocurrido en este hábitat es la agricultura, y la agricultura es el origen del Estado (ZAVALETA, 1990, p. 195).

Portanto, o autor mostra-se cuidadoso para não simplificar demasiadamente o problema, evitando cair numa dicotomia ocidental versus oriental, pois lhe importa muito mais compreender os traços particulares da sociedade civil de casos nacionais específicos. No artigo Problemas de la determinación dependiente y la forma primordial, o autor afirma: "México, que en esto es un verdadero prototipo, podía configurarse en el momento de la explosión social de 1910 como una sociedad civil gelatinosa, es decir, desarticulada en sus elementos e incapaz de producir determinaciones homogéneas hacia el poder" (ZAVALETA, 2009, p. 313-314).

$\mathrm{Se}$, como dissemos, Gramsci enfatizou em seus textos a continuidade entre sociedade civil e sociedade político no contexto dos Estados ocidentais, o que Zavaleta fará é contestar essa continuidade para a realidade local que ele analisa. No texto Formas de operar del Estado en América Latina (bonapartismo, populismo, autoritarismo) há uma passagem bastante significativa sobre isso: "El bonapartismo resulta sin duda una forma particular de ajuste entre el Estado político y la sociedad civil. Está claro que una y otra han entrado en una relación de no conformidad que debe remediarse de modo" (ZAVALETA, 2006, p. 34). O que esta passagem revela? Ela demonstra que na visão de Zavaleta não há uma continuidade necessária, ou uma complementaridade, entre sociedade civil e Estado político. Ao contrário, para o autor, esta relação é vista como variável, comportando uma série de formas de 
interação que nem sempre são harmoniosas. E é exatamente a possibilidade dessa variedade que, na abordagem de Zavaleta, torna relevante os estudos de caso.

O principal método utilizado por ele para dar conta deste objetivo é o método histórico-comparativo. Nisso há também semelhanças com Gramsci, pois o italiano utilizou amplamente a comparação histórica para compreender as particularidades dos intelectuais italianos. O emprego do método histórico comparativo aparece de forma clara no artigo El Estado na América Latina (ZAVALETA, 1990), onde o autor vai trabalhando os contrastes das formações estatais em países como Brasil, Argentina, Chile, Cuba, México dentre outros. É na discussão com Gramsci, especialmente sobre o conceito de Estado como espaço articulado de dois planos da superestrutura (sociedade política e sociedade civil) que Zavaleta propóe o conceito de equação social, que também aparece em outros momentos como eixo estatal. $\mathrm{O}$ que significa este conceito e o que pretende explicar?

$\mathrm{O}$ conceito de equação social parece cumprir o objetivo de explicar a variabilidade de formas como se articulam a sociedade civil e o Estado na realidade latino-americana sem demasiadas preocupações classificatórias (ocidental ou oriental). No artigo El Estado en América Latina, a definição é a seguinte: "Por sistema social o ecuación entendemos entonces el modo de entrecruzamiento entre la sociedad civil, las mediaciones y el momento político-estatal" (ZAVALETA, 1990, p. 178). O mesmo conceito aparece também no artigo Problemas de la determinación dependiente y la forma primordial, evidenciando que foi incorporado ao arsenal teórico do autor: "Por eje estatal entendemos el tipo de relación que hay entre la sociedad civil, las estructuras de mediación y el Estado político" (ZAVALETA, 2009, p. 310).

Assim, o autor está atento não só às continuidades entre sociedade civil e Estado, mas também às suas tensões, desproporçôes e sobreposições. Em outras palavras, Zavaleta parece conceber a existência do Estado sempre em sua relação contraditória com a sociedade, relação esta que constitui a própria exterioridade aparente do Estado frente à sociedade. Ou seja, não há uma regra pré-estabelecida para se resolver as tensóes existentes entre sociedade civil e Estado. São esses processos que o conceito de equação social pretende abarcar. Em outro artigo, o mesmo afirma:

Por razones propias de cada caso, hay ecuaciones en las que la sociedad es más robusta y activa que el Estado, ecuaciones donde el Estado parece preexistir y dominar sobre la sociedad, al menos durante períodos 
determinados, y sistemas donde hay una relación de conformidad o ajuste (ZAVALETA, 1990, p. 177).

$\mathrm{Na}$ perspectiva de Zavaleta, o trabalho propriamente analítico do cientista social seria o de verificar as diferentes formas como se deu a articulação entre sociedade civil e Estado e seus determinantes históricos em cada caso. Em clara consonância com esta ideia, o autor argumenta

La propia sociedad civil, con todo, puede tener una constitución con mayor o menor concurrencia estatal. Es un hecho que la sociedad más sana, desde el punto de vista capitalista, es aquella en que la burguesía ha podido implantar su hegemonía sin el recurso al Estado, como ocurrió en la Francia prerrevolucionaria. Por el contrario, el grado de autonomía societaria del acto hegemónico es casi un coeficiente del desarrollo estatal, porque el Estado debe intervenir más donde hay menos desarrollo de la sociedad civil. Por su parte, no hay duda de que el Estado mismo puede ser más instrumental, más burocrático-hegeliano o más popularestructural. Lo decisivo en todo caso es retener el carácter móvil, cambiable y aleatorio de las instancias (ZAVALETA, 1990, p. 178).

Em outros termos, podemos constatar que na visão de Zavaleta a posição que a sociedade civil e o aparelho estatal ocupam no interior da superestrutura não são fixos ou previamente definidos. Quer dizer, a própria constituição desses espaços como instâncias de exercício do poder de classe e como instrumentos de manutenção ou transformação da ordem social se constituem historicamente por vias nacionais com certo grau de originalidade. Neste sentido, o que as teorias gerais sobre o Estado fizeram foi generalizar no âmbito teórico alguns modelos encontrados empiricamente, o que não supera a necessidade de se continuar estudando outros casos empíricos. A análise concreta dos casos latino-americanos revela a originalidade da leitura que Zavaleta faz da concepção ampliada de Estado de matriz gramsciana: trata-se de compreender o tipo de relação que se estabelece entre sociedade civil e Estado, relação esta que na concepção do autor é variável e historicamente constituída.

\section{Conclusões}

Buscamos neste artigo abordar a recepção por Zavaleta da obra de Gramsci, especificamente a forma como o sociólogo boliviano se apropriou do conceito de Estado e o considerou para a realidade latino-americana. Ressaltamos a relevância 
desta reflexão especialmente pela importância de Zavaleta para o pensamento social do nosso continente e esperamos que este artigo contribua para que os brasileiros passem a conhecer a obra deste autor.

Constatamos que o esforço de Zavaleta foi o de buscar compreender as características particulares dos Estados latino-americanos em claro diálogo com a teoria marxista, em especial, com Gramsci. Podemos dizer que o ponto de partida de Zavaleta foi a dificuldades de interpretar os fenômenos políticos nas zonas periféricas do capitalismo com os mesmos instrumentos de análise forjados para interpretar as regiōes de capitalismo desenvolvido. Neste caminho, ao invés de negar a contribuição europeia sobre o tema do Estado, Zavaleta parece ter encontrado em Gramsci uma base teórica adequada para enfrentar este problema de pesquisa. $\mathrm{O}$ sociólogo boliviano encontra em Gramsci uma perspectiva capaz de combinar as determinaçôes da dinâmica econômica do capitalismo periférico sobre as formaçóes estatais latinoamericanas, e a respectiva natureza de classe do Estado, com a autonomia da esfera política e seu alto grau de originalidade histórica nacional.

Verificamos que a preocupação central demonstrada por Zavaleta era a de compreender a forma do Estado. Zavaleta maneja o conceito de Estado em dois sentidos distintos e complementares: enquanto forma de dominação determinada pelo desenvolvimento econômico da sociedade - e sua estrutura de classes - e enquanto aparato específico de dominação política. Esta dualidade também se encontra em Gramsci, ou seja, um significado restrito e outro ampliado de Estado. Além disso, o boliviano também dá centralidade à sociedade civil na análise que faz das configuraçôes estatais latino-americanas.

Neste caminho, Zavaleta propóe uma abordagem original que destoa inclusive de outros autores latino-americanos que trataram o tema do Estado na América Latina a partir de Gramsci. Aliás, destaca-se nos três artigos analisados a notável ausência de uma discussão específica de Zavaleta com outros autores que traduziram Gramsci na América Latina. Ademais, nota-se também a ausência de uma abordagem sobre o papel dos intelectuais na dinâmica estatal, tema caro a Gramsci, como se sabe.

Encontramos no conceito de equação social ou eixo estatal formulado por Zavaleta esta possibilidade de análise da relação entre Estado (restrito) e sociedade civil. O conceito de equaçáo social ou eixo estatal aparece como uma ferramenta analítica para a compreensão da variabilidade histórica do Estado no seu sentido ampliado, capaz de contemplar as diferentes experiências nacionais sem eliminar a capacidade explicativa geral dos conceitos. 
Por fim, ressaltamos a necessidade de maiores estudos sobre a influência de Gramsci na obra de Zavaleta. Não está claro, por exemplo, em que momento de sua vida e por quais caminhos Zavaleta começou a ler os textos de Gramsci. Um estudo desta envergadura dependeria de uma leitura de conjunto da obra do boliviano, desde sua juventude politicamente engajada até sua plena maturidade intelectual e acadêmica no México. Certamente esta reconstrução ajudaria a pensar de que forma e a partir de que temas e problemas se deu a incorporação de Gramsci na obra do sociólogo boliviano.

- Lauro Allan Almeida Duvoisin é Mestre em História Social, Doutorando em Ciência Politica, pela Universidade Federal do Rio Grande do Sul (UFRGS), membro do Grupo de Pesquisa Cultura Política, Estado e Relações Internacionais (UFRGS) e do Grupo World Values Survey (WVS - Brasil). E-mail: lauroallanalmeida@, gmail.com.

- Sonia Maria Ranincheski é Doutora em Sociologia, pela Universidade de Brasília, Professora do Programa de PósGraduação em Ciência Política da UFRGS; Líder do grupo de pesquisa CESPRI e Investigadora Adjunta do WVS e Vice-Diretora Nacional para o Brasil. Email: sonia.ranincheski@ufrgs.br

\section{Referências}

ARICÓ, José. O itinerário de Gramsci na América Latina. Estudos de Sociologia, v.1, n. 5, p. 1-34, 1998.

BÓRQUEZ, Elveira. René Zavaleta: una mirada comprometida. In: IBARGÜEN, Maya; MÉNDEZ, Norma (Orgs.). René Zavaleta Mercado: Ensayos, testimonios y re-visiones. Buenos Aires: Miño y Dávila editores, 2006, p. 179-188.

BUCI-GLUCKSMANN, Christinne. Gramsci e o Estado. 2a Ed. Rio de Janeiro: Paz e terra, 1980.

CABALUZ, Fabián. La especificidad del Estado en América Latina. Apuntes a partir de la obra de René Zavaleta Mercado. Izquierdas, v.1, n. 38, p. 240-256, 2018.

CAMPIONE, Daniel. Para leer a Gramsci. Buenos Aires: Centro Cultural de la Cooperación Floreal Gorini, 2007. 
COUTINHO, Carlos. Gramsci e o sul do mundo: entre oriente e ocidente. Margem Esquerda, v. 1, n. 5, p. 122-130, 2012.

CUEVA, Augustín; OBERDIEK, Hermann; TOMAZI, Nelson. A concepção marxista de classes sociais. Revista mediaçóes, v. 2, n. 2, p. 69-79, 1997.

GRAMSCI, Antonio. Cuadernos de la cárcel - Tomo 1. 2a ed. Pueblo: Era, 1999a.

Cuadernos de la cárcel - Tomo 2. 2a ed. Puebla: Era; 1999b.

Cuadernos de la cárcel - Tomo 3. [s.l.] Era, 1968.

Cuadernos de la cárcel - Tomo 4. México: Era, 1986.

HOBSBAWM, Eric. Sobre História. São Paulo: Companhia das Letras, 1998.

IBARGÜEN, Maya; MÉNDEZ, Norma. René Zavaleta Mercado: Ensayos, testimonios y re-visiones. Buenos Aires: Miño y Dávila editores, 2006.

MARX, Karl. Contribuição à crítica da economia politica. $2^{a}$ ed. São Paulo: Expressão Popular, 2008. . O 18 de brumário de Luís Bonaparte. São Paulo: Boitempo, 2011.

MENDONÇA, Sonia. O Estado ampliado como ferramenta metodológica. Marx e o marxismo, v. 2, n. 2, p. 27-43, 2014.

MORALES, Hugo. Zavaleta: narratividad autobiográfica y socialismo local. In: IBARGÜEN, Maya; MÉNDEZ, Norma (Orgs.). René Zavaleta Mercado: Ensayos, testimonios y re-visiones. Buenos Aires, 2006, p. 111-144.

MUNCK, Ronaldo. Rethinking Latin America Back to the Future? Latin American Perspectives, v. 42, n. 4, p. 73-91, 2015.

PACHECO, Mario. Memoria en los caminos a Bayamo. In: IBARGÜEN, Maya; MÉNDEZ, Norma (Orgs.). René Zavaleta Mercado: Ensayos, testimonios y re-visiones. Buenos Aires, 2006, p. 65-75.

PIZZORNO, Pablo. Populismo y revolución pasiva. Sobre "los usos de Gramsci" en América Latina. Revista Torres de Lucca, v. 6, n. 11, p. 97-130, 2017.

PORTANTIERO, Juan. Los usos de Gramsci. [s.l.] Folios Ediciones SA, 1981.

PORTELLI, Hugues. Gramsci e o bloco histórico. 6a ed. Rio de Janeiro: Paz e terra, 2002.

PUCHET, Martín. Formas de pensar y hacer de René Zavaleta. Una evocación. In: IBARGÜEN, Maya; MÉNDEZ, Norma (Orgs.). René Zavaleta Mercado: Ensayos, testimonios y re-visiones. Buenos Aires, 2006, p. 83-92.

QUEVEDO, Cecilia. La categoría de "formación social” en lecturas latinoamericanas. Cuadernos del pensamiento latinoamericano, v.1, n. 21, p. 85-104, 2014.

RADA, Paola. Estado y estatalidad en René Zavaleta Mercado y Álvaro García Linera. Bolivian Research Review/Revista Boliviana de Investigación, v. 11, n. 1, p. 90-101, 2014.

ROJAS, Odín. A. La influencia del pensamiento marxista de Antonio Gramsci en la concepción sobre el Estado de René Zavaleta Mercado. Revista Kavilando, v. 9, n. 2, p. 321-574, 2017.

SECCO, Lincoln. A pré-história de Gramsci no Brasil (1927-1974). Novos Rumos, v.1, n. 32, p. 1628, 2000.

TAPIA, Luis. Prólogo. In: TAPIA, Luis (Org.). La autodeterminación de las masas. Bogotá: CLACSO, 2009a, p. 9-29.

. Bibliografía y hemerografía de René Zavaleta. In: TAPIA, Luis (Org.). La autodeterminación de las masas. Bogotá: CLACSO, 2009b, p. 385-392.

WILLIAMS, Gareth. Social Disjointedness and State-Form in Álvaro García Linera. Culture, Theory \& Critique, v. 56, n. 3, p. 297-313, 2015. 
ZAVALETA, René. El Estado en América Latina. In: El estado en América Latina. La Paz: Editorial Los Amigos del Libro, 1990, p. 161-203.

Formas de operar del Estado en América Latina (bonapartismo, populismo, autoritarismo). In: IBARGÜEN, Maya; MÉNDEZ, Norma (Orgs.). René Zavaleta Mercado: Ensayos, testimonios y re-visiones. Buenos Aires, 2006, p. 33-54.

. Problemas de la determinación dependiente y la forma primordial. In: TAPIA, L. (Org.). La autodeterminación de las masas. Bogotá: CLACSO, 2009, p .291-320.

Texto recebido em 14 de dezembro de 2018. Aprovado em 06 de fevereiro de 2019. 